\title{
Airway responsiveness to hypertonic saline: dose-response slope or PD15?
}

\author{
G. de Meer*, G.B. Marks" ${ }^{\#}$, J.C. de Jongste ${ }^{\star}$ and B. Brunekreef*
}

ABSTRACT: The result of airway challenge test with hypertonic saline (HS) is expressed as the dose causing a $15 \%$ fall in forced expiratory volume in one second (FEV1; PD15). A noncensored measure, such as the dose-response slope (DRS), allows the evaluation of the risk of asthma for subjects with a fall in $\mathrm{FEV}_{\mathbf{1}}<\mathbf{1 5 \%}$. The aim of this study was to assess the relationship between airway responsiveness to HS by PD15 or DRS, asthma symptoms and markers of eosinophilic inflammation.

Data on current wheeze and airway responsiveness were obtained for 1,107 children (aged 8$13 \mathrm{yrs}$ ). Blood eosinophils and serum eosinophil cationic protein (ECP) were assessed in subsets ( $n=683$ and 485). PD15 was assessed if FEV 1 fell $\geqslant 15 \%$, and the DRS was calculated for all tests. Graphs were constructed to visualise relationships with current wheeze, blood eosinophils and serum ECP. Odds ratios and Spearman's correlation coefficients were calculated to quantify these relationships.

Children with features of asthma had lower PD15 and higher DRS, and separation was most pronounced for DRS. Prevalence of current wheeze increased continuously over the entire range of DRS values. Blood eosinophils were significantly higher only for the highest values of DRS.

In conclusion, the continuous relationship between airway responsiveness and asthma symptoms is in favour of a noncensored measure of airway responsiveness, such as the doseresponse slope.

KEYWORDS: Airway hyperresponsiveness, childhood asthma, dose-response slope, epidemiology, hypertonic saline, provocative dose causing a $15 \%$ fall in forced expiratory volume in one second

W orldwide, airway challenge with hypertonic saline (HS) is performed in childhood population studies that adhere to the International Study on Allergy and Asthma in Childhood (ISAAC) [1]. HS is an indirect stimulus that causes bronchoconstriction, presumably by the release of inflammatory mediators from intermediary cells. There is evidence to suggest that, in children with asthma, airway hyperresponsiveness (AHR) to HS is more closely related to the underlying airway inflammation than AHR to direct stimuli, such as methacholine or histamine $[2,3]$.

Conventionally, AHR to HS is considered to be present if the forced expiratory volume in one second (FEV1) falls by $\geqslant 15 \%$ fall after inhalation of a provocative dose of $\leqslant 23 \mathrm{~g}$ HS (PD15 $\leqslant 23 \mathrm{~g}$ ), which is the cumulative dose after $15.5 \mathrm{~min}$ inhalation at a minimal nebuliser output of $1.5 \mathrm{~mL} \cdot \mathrm{min}^{-1}$ [1]. According to this definition, the presence of AHR to HS has a specificity of up to $92 \%$ for asthma symptoms in the past 12 months and a doctor's diagnosis of asthma [4]. In children with AHR, the PD15 provides a measure of severity of airway hyperresponsiveness. However, PD15 can only be assessed in individuals with AHR and will be of limited value in general population studies in which the prevalence of AHR is modest. It is not clear whether subjects who have a sub-threshold (i.e. $<15 \%$ ) fall in FEV1 have an increased probability of asthma symptoms and pathology compared to nonresponsive subjects. For methacholine and histamine challenge test, attempts have been made to develop a measure of airway responsiveness below the threshold of AHR [5-8], of which the dose-response slope (DRS) that reflects the fall in FEV1 per unit substance inhaled is generally accepted. So far, no studies have been published on the comparison of different measures of airway responsiveness using indirect stimuli, such as HS

In community populations, DRS to methacholine or histamine is associated with asthma diagnosis
AFFILIATIONS

*Institute for Risk Assessment

Sciences, Environmental and

Occupational Health, Utrecht

University, Utrecht, and

\#Childhood Pulmonology, Erasmus

Medical Centre, Rotterdam, The

Netherlands.

'Woolcock Institute of Medical

Research, Sydney

New South Wales, Australia.

CORRESPONDENCE

G. de Meer

Institute for Risk Assessment

Sciences

Environmental and Occupational

Health

Utrecht University, P.0. Box 80176

3508 TD Utrecht

The Netherlands

Fax: 31302535077

E-mail: G.demeer@iras.uu.nl

Received

January 212004

Accepted after revision:

September 222004

SUPPORT STATEMENT

This study was supported by the Netherlands Asthma Foundation (NAF) and the Ministry of Housing and Environmental Protection, The Hague, The Netherlands. G. de Meer was supported by grants from the Netherlands Asthma Foundation (NAF) and Utrecht University, Utrecht, The Netherlands. 
and symptoms [8-14]. However, studies that compare the discriminative power of DRS and provocative dose causing a $20 \%$ fall in FEV1 are scarce and have yielded conflicting results. ABRAMSON et al. [9] found better separation of asthmatics and nonasthmatics by DRS [9], whereas no difference was observed by CHINN et al. [8]. However, protocols and prevalence of AHR differed considerably for both studies, which may have affected the results. Neither of these studies has evaluated the relationship of DRS with symptoms below the threshold of AHR separately. Therefore, it cannot be excluded that the positive associations found in previous studies result from strong relationships in the uppermost tail of DRS values. If so, a continuous measure of airway responsiveness should be avoided.

The aim of the present study was to evaluate DRS and PD15 as measures of airway responsiveness to $H S$ in a general childhood population. Using graphical techniques, the relationship between DRS and asthma symptoms was examined. The current authors were particularly interested to see whether a cut-off point that marks a detectable rise in prevalence of asthma symptoms for DRS could be determined. Similarly, the relationship between DRS and markers of eosinophilic inflammation, i.e. blood eosinophils and serum eosinophil cationic protein (ECP), was evaluated.

\section{METHODS}

\section{Study population and design}

This study was part of a cross-sectional survey on the respiratory health effects of living close to a freeway. A detailed description of the study protocol has been published previously [15]. Briefly, children of grades 4-8 (aged 8-13 yrs) from 24 primary schools located within $400 \mathrm{~m}$ of a freeway were invited to participate (south-western regions of The Netherlands). All schools adhered to the Dutch public school system, and may be regarded as a representative sample of primary schools in The Netherlands. Parents completed the ISAAC questionnaire on allergic and respiratory symptoms. Children $\geqslant 8$ yrs old were invited for skin-prick testing, airway challenge with HS and blood withdrawal (immunoglobulin (Ig)E, eosinophil counting). Serum ECP was assessed in a casecontrol sample, in which cases were defined by the presence of "ever-wheeze", "ever-asthma" or "dry cough in the past 12 months". For each case, two control children were chosen without any of the previously outlined symptoms. The parents gave informed consent for each test separately. The Medical Ethical Board of the University of Wageningen, Wageningen, The Netherlands, approved the study protocol.

For the current analyses, children aged $\geqslant 8$ yrs $(n=2,207)$ were included, in whom data were obtained for the presence of wheeze in the past 12 months $(n=2,159)$ and for the completion of the bronchial challenge test $(n=1,107)$. Blood eosinophil counting occurred in 682 of these children. Serum ECP was assessed in 485 children of whom $34 \%$ were cases as defined previously, which was similar to the number of cases in children without ECP assessment (32\%) and can therefore be regarded a representative sample.

\section{Questionnaire}

The ISAAC core questionnaire was completed by one of the parents or carers. For the current study, "current wheeze" was defined as if a child had a history of wheeze in the past 12 months, and "ever-asthma" was defined as if parents confirmed a history of asthma.

\section{Blood eosinophils and serum eosinophil cationic protein}

Blood eosinophils were determined by Coulter counter autoanalyser (AML, Anvers, Belgium) and expressed as the number of cells per L.

Serum ECP was determined by fluoro-immunoassay, by the same lab that performed IgE analyses (Pharmacia, Woerden, The Netherlands). Blood and serum handling occurred according to the test manufacturer's protocol.

\section{Hypertonic saline challenge}

Airway challenge with HS (4.5\%) was performed according to the protocol approved by the ISAAC steering committee [3]. Salbutamol was withheld $6 \mathrm{~h}$ before the airway challenge test, and antihistaminics and cromoglycate at $48 \mathrm{~h}$. Baseline lung function was assessed according to European Respiratory Society guidelines, using a pneumotachometer (Jaeger, Würzburg, Germany). Informed consent for the airway challenge test was obtained for 1,379 children who completed questionnaire data. A total of 146 children were excluded, because of inability to perform satisfactory forced spirometry manoeuvres $(n=130)$, or a baseline FEV1 $<75 \%$ of the predicted value according to ZAPLETAL et al. [16] $(n=16)$. Another 126 tests were discarded because of excessive cough, unwillingness or inability to perform acceptable spiromety.

The protocol comprised of inhalation of $4.5 \%$ HS aerosol generated by an ultrasonic nebuliser closed system (Jaeger), for $0.5,1,2,4$ and $8 \mathrm{~min}$ (total: $15.5 \mathrm{~min}$ ). During the study period, nebuliser output did not fall below $1.5 \mathrm{~mL} \cdot \mathrm{min}^{-1}$, which is the minimal level, according to the ISAAC protocol [3]. After each dose step, two reproducible measurements of FEV1 were assessed, of which the higher was selected. If FEV1 fell 10-15\% compared with pre-challenge FEV1, the same dose step was repeated. The test stopped after a total inhalation time of $15.5 \mathrm{~min}$, or if FEV1 fell $\geqslant 15 \%$. Salbutamol was administered to relieve airflow limitation or symptoms when needed. The amount of inhaled HS was assessed by the difference in canister weight prior to and after the test. PD15 was calculated by linear interpolation between the last two points of the dose response curve where FEV1 fell $\geqslant 15 \%$. AHR was defined by a PD15 $\leqslant 23.0 \mathrm{~g}$. The DRS was assessed for all tests by dividing the $\%$ fall in FEV1 from pre-challenge FEV1 by the amount of HS inhaled [5].

\section{Statistical analysis}

Graphs were constructed to visualise the relationships between DRS and current wheeze, blood eosinophils or serum ECP. DRS values were stratified according to the \% fall in FEV1. For each stratum, the prevalence rate and odds ratios (OR) with $95 \%$ confidence intervals of current wheeze were assessed. Differences in PD15 and DRS between children with and without current wheeze and ever-asthma, respectively, were assessed by t-test. Prior, DRS values were log transformed to normalise residuals. A constant of 1.0 was added to all DRS values to eliminate negative values that occurred if lung function improved during the challenge test. Discriminatory capacities of DRS and PD15 for ever-asthma and current 


\begin{tabular}{|c|c|}
\hline \multicolumn{2}{|l|}{ Characteristics } \\
\hline Mean age yrs & $10(8-13)$ \\
\hline Females & $534(48)$ \\
\hline Current wheeze & $194(18)$ \\
\hline Ever-asthma ${ }^{\#}$ & $91(8)$ \\
\hline Inhaled corticosteroid treatment & $42(4)$ \\
\hline Mean FEV1 & $100(75-168)$ \\
\hline AHR & $225(20)$ \\
\hline Geometric mean DRS & $0.70(-0.80-14.30)$ \\
\hline Median blood eosinophils $\times 10^{6} \cdot \mathrm{L}^{-19}$ & $210(1-2190)$ \\
\hline Median serum $\mathrm{ECP}^{+}$ & $5.9(2.0-201.0)$ \\
\hline \multicolumn{2}{|c|}{$\begin{array}{l}\text { Data are presented as mean (range), } n(\%) \text { and median (range). FEV1: forced } \\
\text { expiratory volume in one second; AHR: airway hyperresponsiveness; DRS: } \\
\text { dose-response slope; ECP: eosinophil cationic protein. } \#: n=1,095 ;{ }^{\circ}: n=682 \text {; } \\
+: n=485 \text {. }\end{array}$} \\
\hline
\end{tabular}

wheeze were assessed by dividing the mean difference by the standard deviation [17].

Since no assumptions were made on the normality of the distribution and linearity of the relationship between the parameters, Spearman's correlation coefficients were calculated as correlation measures for the relationships between DRS, blood eosinophils and serum ECP.

\section{RESULTS}

The study population comprised 1,107 children with complete data on current wheeze and airway challenge. Blood eosinophils were assessed in 682 and serum ECP in 485 children. There was no difference in sex, paternal asthma, passive smoking, diagnosed asthma and current wheeze between children with and without data for airway responsiveness, blood eosinophil counting or serum ECP. Table 1 shows the characteristics of the study population. In 32 children (3\%), the predicted value for FEV1 exceeded $120 \%$ [16]. During the challenge test, FEV1 increased in 30 children ranging 0.2 $14.9 \%$, and increased $>5 \%$ in six children.

Figure 1 shows the relationship between levels of DRS and current wheeze. The prevalence of wheeze increases with increasing DRS values (fig. 1a). This also exists for DRS values below the threshold of AHR. Similarly, there is a linear increase in OR of current wheeze with increasing levels of DRS (fig. 1b). Both indices of airway responsiveness discriminated between children with and without asthma features, i.e. current wheeze and ever-asthma (tables 2 and 3). The discriminatory capacity, as indicated by the mean difference divided by the standard deviance, was higher for log DRS than for PD15.

Figure 2 shows the relationship between DRS and blood eosinophilic markers, stratified for the presence of current wheeze. Both blood eosinophils (fig. 2a) and serum ECP (fig. 2b) were higher in symptomatic children. The figures suggest a relationship only for the highest values of DRS that
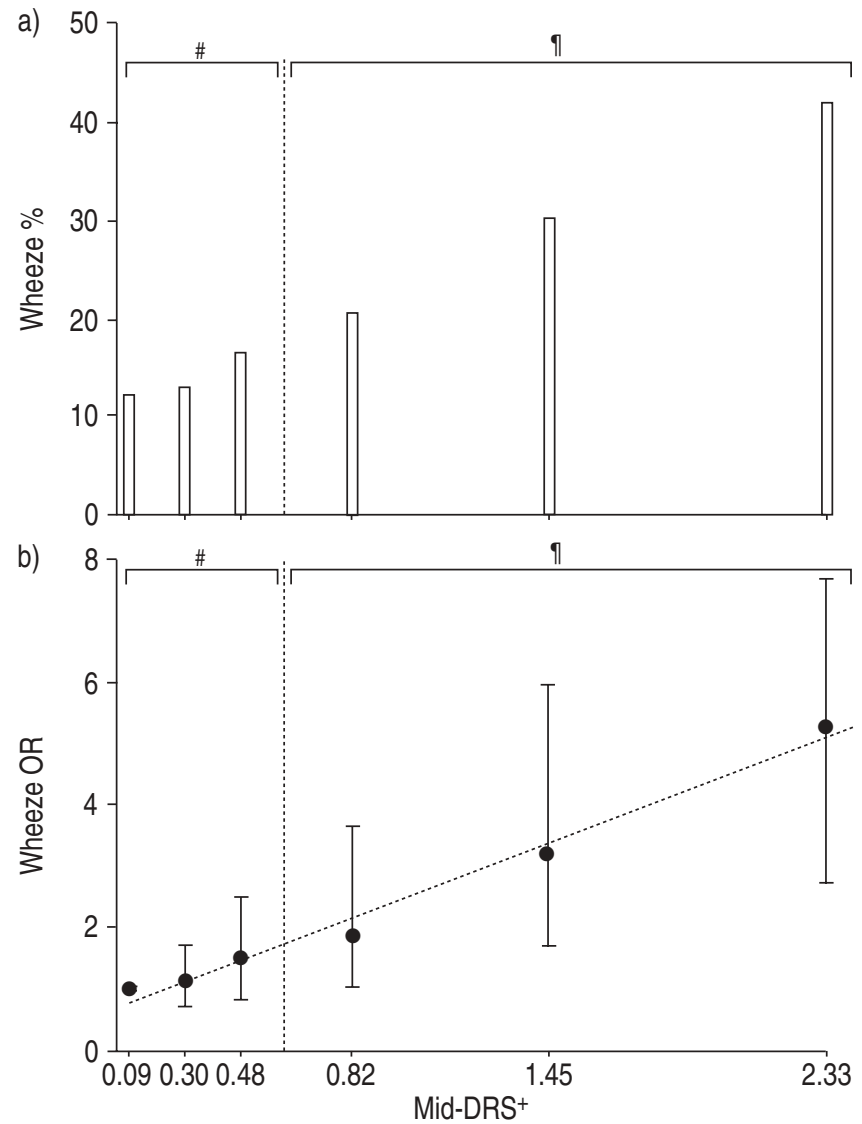

FIGURE 1. The relationship between levels of dose-response slope (DRS) and current wheeze given by a) prevalence rate of current wheeze per stratum of DRS and b) odds ratios (OR) for current wheeze and 95\% confidence intervals per stratum of DRS. The strata for DRS are defined by a fall in forced expiratory volume in one second of $\leqslant 5 \%, 5-7.5 \%, 7.5-10 \%, 10-15 \%, 15-25 \%, 25-45 \%$ and $45-70 \%$.

....: threshold of airway hyperresponsiveness (AHR). \#: below the AHR threshold

๑: above the AHR threshold; ${ }^{+}$: median DRS per stratum.

exceeded the threshold value for AHR. Spearman's correlation coefficients confirmed no relationship below the threshold of AHR, and a statistically significant correlation for blood eosinophils in children with AHR and current wheeze (table 4). Corticosteroid treatment aims to reduce inflammation and may, therefore, affect the results. After exclusion of

\begin{tabular}{|c|c|c|c|c|c|c|}
\hline \multirow[t]{3}{*}{ TABLE 2} & \multicolumn{6}{|c|}{$\begin{array}{l}\text { Dose-response slope (DRS) and PD15 in children } \\
\text { with and without current wheeze }\end{array}$} \\
\hline & \multicolumn{2}{|c|}{$\begin{array}{l}\text { Current } \\
\text { wheeze }\end{array}$} & \multicolumn{2}{|c|}{$\begin{array}{l}\text { No current } \\
\text { wheeze }\end{array}$} & \multirow[t]{2}{*}{$p$-value } & \multirow[t]{2}{*}{$\mathrm{D} / \mathrm{sD}$} \\
\hline & $\mathbf{n}$ & Mean & $\mathbf{n}$ & Mean & & \\
\hline Log DRS & 194 & 1.41 & 913 & 0.55 & $<0.001$ & 0.63 \\
\hline PD15 & 77 & 0.79 & 148 & 0.94 & $<0.001$ & 0.48 \\
\hline
\end{tabular}

PD15: provocative dose causing a $15 \%$ fall in forced expiratory volume in one second; D/SD: mean difference divided by the standard deviation. 


\begin{tabular}{|c|c|c|c|c|c|c|}
\hline \multirow[t]{3}{*}{ TABLE 3} & \multicolumn{6}{|c|}{$\begin{array}{l}\text { Dose-response slope (DRS) and PD15 in children } \\
\text { with and without ever-asthma }\end{array}$} \\
\hline & \multicolumn{2}{|c|}{ Ever-asthma } & \multicolumn{2}{|c|}{ No ever-asthma } & \multirow[t]{2}{*}{ p-value } & \multirow[t]{2}{*}{$D / S D$} \\
\hline & $\mathbf{n}$ & Mean & $\mathbf{n}$ & Mean & & \\
\hline Log DRS & 91 & 1.54 & 1004 & 0.63 & $<0.001$ & 0.65 \\
\hline PD15 & 39 & 7.27 & 186 & 10.38 & 0.003 & 0.52 \\
\hline
\end{tabular}

these children, the correlation coefficient for blood eosinophils in symptomatic children increased $(r=0.34 ; \mathrm{p}=0.03)$.

\section{DISCUSSION}

This large-scale, population-based sample of school children aged 8-13 yrs demonstrates a continuous increase in the risk of current wheeze with increasing airway responsiveness to HS, even below the threshold of AHR. This result supports the use of a continuous measure, such as the DRS, to express the results of bronchial challenge testing.

In this study population, no arguments for selection bias were found, since prevalence rates of asthma features and general characteristics were similar among children who participated in bronchial challenge testing and those who did not. Nevertheless, selection cannot be completely ruled out, since no information was collected for children without questionnaire data.

Airway responsiveness was higher in children with asthma features, both for DRS and PD15, although discrimination was highest for DRS. The DRS allows the assessment of airway responsiveness for all individuals, including those who do not reach the threshold of AHR. It was hypothesised that this would be an advantage if there was a relationship with asthma features at levels of DRS below AHR. In this population, it has been clearly shown that the risk of asthma symptoms increased over the whole range of DRS values, including those below the threshold of AHR. To the current authors' knowledge, this is the first study in which separate analyses were performed for both sides of the threshold defining AHR. Previous studies found higher values for DRS in subjects with asthma features, but did not evaluate subjects without AHR separately [8,9]. Hence, the positive association between asthma symptoms and DRS may have occurred predominantly in subjects with AHR who will have highest DRS values.

Another method to obtain results of airway challenge testing for all individuals is censoring PD15 to a fixed value in subjects without AHR. This procedure, however, limits statistical analyses due to its extreme, skewed distribution. Expressing the results of bronchial challenge test with $\mathrm{HS}$ by a dichotomous variable, such as AHR, or by a censored measure, such as PD15, does not address the continuous relationship between asthma features and airway responsiveness without a threshold, as observed in this study population.
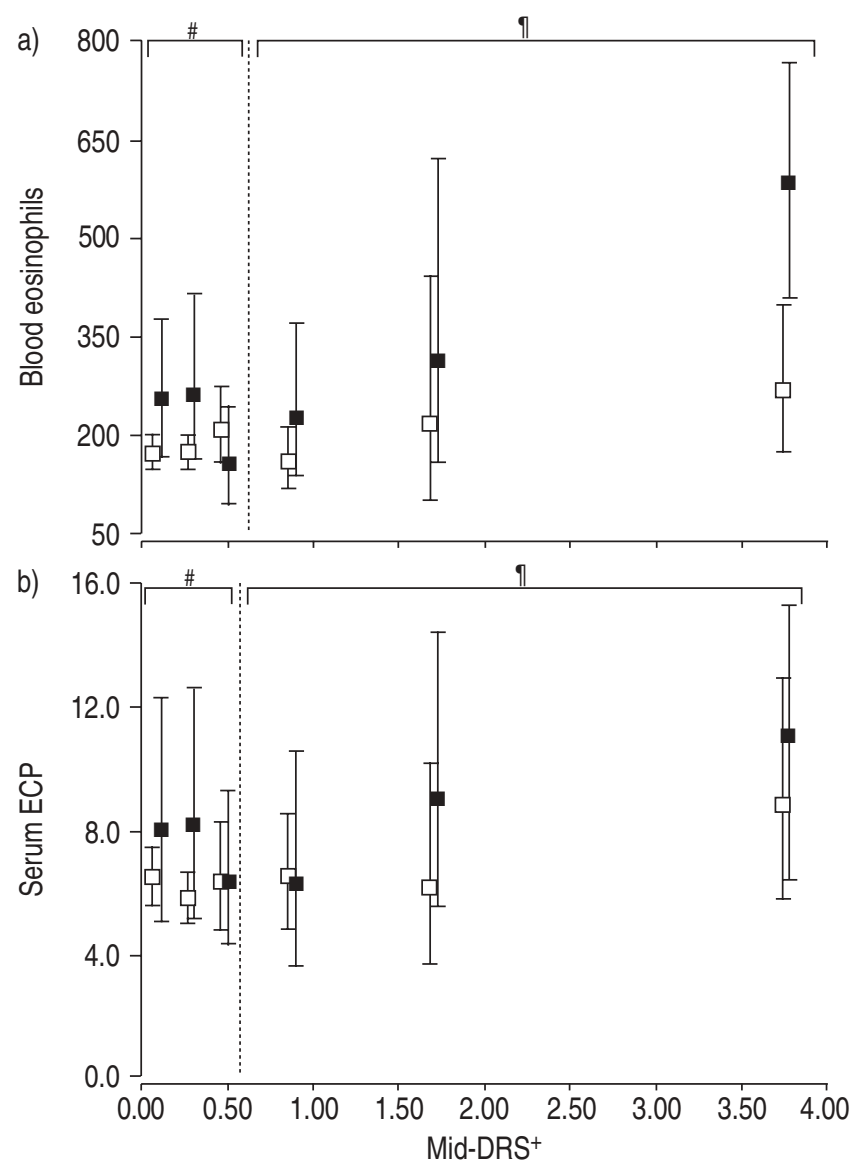

FIGURE 2. Inflammatory markers (a) blood eosinophils and b) serum eosinophil cationic protein (ECP)) by dose-response slope (DRS) in children with ( $\mathbf{\square})$ and without ( $\square$ ) current wheeze. Data are presented as the geometric mean and 95\% confidence interval per stratum of DRS. The strata for DRS are defined by a fall in forced expiratory volume in one second of $\leqslant 5 \%, 5-7.5 \%, 7.5-10 \%, 10-15 \%, 15-25 \%, 25-45 \%$ and $45-$ $70 \%$. …: threshold of airway hyperresponsiveness (AHR). \#: below the AHR threshold; ${ }^{\bullet}$ : above the AHR threshold; ${ }^{+}$: median DRS per stratum.

\begin{tabular}{|c|c|c|c|c|c|}
\hline \multirow[t]{3}{*}{ TABLE 4} & \multicolumn{5}{|c|}{$\begin{array}{l}\text { Spearman's correlation coefficients (r) for dose- } \\
\text { response slope, blood eosinophils, and serum } \\
\text { eosinophil cationic protein (ECP) by airway } \\
\text { hyperresponsiveness (AHR) and current wheeze }\end{array}$} \\
\hline & & \multicolumn{2}{|c|}{ Without AHR } & \multicolumn{2}{|c|}{ With AHR } \\
\hline & & $\mathbf{n}$ & $\mathbf{r}$ & n & $\mathbf{r}$ \\
\hline \multicolumn{6}{|c|}{ Blood eosinophils } \\
\hline All children & & 537 & 0.03 & 145 & $0.22^{\star *}$ \\
\hline No current & heeze & 460 & 0.03 & 89 & 0.11 \\
\hline Current wh & & 77 & 0.03 & 56 & $0.26^{*}$ \\
\hline \multicolumn{6}{|l|}{ Serum ECP } \\
\hline All children & & 379 & -0.01 & 106 & 0.10 \\
\hline No current & heeze & 328 & -0.01 & 67 & 0.10 \\
\hline Current wh & & 51 & -0.02 & 39 & 0.03 \\
\hline
\end{tabular}


Airway responsiveness above the threshold of AHR has been found repeatedly to increase the risk of developing asthma [18-22]. Although it has been shown that there is a higher risk of current wheeze in children with low levels of airway responsiveness in this cross-sectional survey, the predictive value of low levels of airway responsiveness for the future development of asthma needs to be confirmed in follow-up studies.

An attempt was made to study the relationship between airway responsiveness and eosinophilic inflammation by including analyses on blood eosinophils and serum ECP. A positive correlation was observed between blood eosinophils and airway responsiveness, though only if airway responsiveness exceeded the threshold of AHR.

The relationship between DRS and asthma symptoms below the threshold of AHR was not accompanied by a similar relationship of DRS in this range with blood eosinophilic markers. This discrepancy may be due to differences in the time course of these variables. While symptoms refer to a period of the past 12 months, eosinophilic markers presumably reflect a shorter period of time. Since airway responsiveness below the level of AHR was only associated with asthma symptoms, it is suggested that airway responsiveness to hypertonic saline also reflects longer-term airway abnormalities. Other explanations may be a lack of sensitivity for blood eosinophilic markers to detect bronchial inflammation [23], or the possibility that airway responsiveness and eosinophilic activation represent different inflammatory pathways [24, 25].

In summary, a positive association between the risk of asthma symptoms and airway responsiveness to hypertonic saline was found, even below the threshold of airway hyperresponsiveness. Blood eosinophils and serum eosinophil cationic protein were only increased at the higher end of the dose-response slope spectrum. In conclusion, in general population studies, the dose-response slope should be preferred to threshold measures, such as provocative dose causing a $15 \%$ fall in forced expiratory volume in one second, to express airway responsiveness. It allows the assessment of airway responsiveness over the entire range, both as determinant and end point. Including all test results increases statistical power, which may benefit study efficacy.

\section{ACKNOWLEDGEMENTS}

The authors would like to thank F. Aarts, P. van Vliet, S. de Wind and B. de Wit for the organisation and conductance of the fieldwork.

\section{REFERENCES}

1 International Study on Allergy and Asthma in Childhood (ISAAC) Phase II modules. Münster, Institute of Epidemiology and Social Medicine, 1998.

2 du Toit JI, Anderson SD, Jenkins CR, Woolcock AJ, Rodwell LT. Airway responsiveness in asthma: bronchial challenge with histamine and $4.5 \%$ sodium chloride before and after budesonide. Allergy Asthma Proc 1997; 18: 7-14.

3 Gibson PG, Saltos N, Borgas T. Airway mast cells and eosinophils correlate with clinical severity and airway hyperresponsiveness in corticosteroid-treated asthma. J Allergy Clin Immunol 2000; 105: 752-759.
4 Riedler J, Reade T, Dalton M, Holst D, Robertson C. Hypertonic saline challenge in an epidemiologic survey of asthma in children. Am J Respir Crit Care Med 1994; 150: 1632-1639.

5 O'Connor G, Sparrow D, Taylor D, Segal M, Weiss S. Analysis of dose-response curves to methacholine. An approach suitable for population studies. Am Rev Respir Dis 1987; 136: 1412-1417.

6 Sherill DL, Martinez FD, Sears MR, Lebowitz MD. An alternative method for comparing and describing methacholine response curves. Am Rev Respir Dis 1993; 148: 116-122.

7 Forastiere F, Pistelli R, Michelozzi P, et al. Indices of nonspecific bronchial responsiveness in a pediatric population. Chest 1991; 100: 927-934.

8 Chinn S, Burney PGJ, Britton JR, Tattersfield AE, Higins BG. Comparison of PD20 with two alternative measures of response to histamine challenge in epidemiological studies. Eur Respir J 1993; 6: 670-679.

9 Abramson MJ, Saunders NA, Hensley MJ. Analysis of bronchial reactivity in epidemiological studies. Thorax 1990; 45: 924-929.

10 Peat JK, Salome CM, Berry G, Woolcock AJ. Relation of dose-response slope to respiratory symptoms in a population of Australian schoolchildren. Am Rev Respir Dis 1991; 144: 663-667.

11 Ulrik CS, Backer V. Longitudinal determinants of bronchial responsiveness to inhaled histamine. Chest 1998; 113 973-979.

12 Ownby DR, Peterson EL, Johnson CC. Factors related to methacholine airway responsiveness in children. Am J Respir Crit Care Med 2000; 161: 1578-1583.

13 De Meer G, Heederik D, Postma DS. Bronchial responsiveness to adenosine 5'-monophosphate (AMP) and methacholine differ in their relationship with airway allergy and baseline FEV(1). Am J Respir Crit Care Med 2002; 165: 327-331.

14 Alvarez-Puebla MJ, Garcia-Figueroa BE, Tabar-Purroy AI, Olaguibel-Rivera JM. Discriminant analysis in allergic rhinitis and asthma: methacholine dose-response slope allows a good differentiation between mild asthma and rhinitis. Respir Med 2003; 97: 30-36.

15 Janssen NA, Brunekreef B, van Vliet $\mathrm{P}$, et al. The relationship between air pollution from heavy traffic and allergic sensitization, bronchial hyperresponsiveness, and respiratory symptoms in Dutch schoolchildren. Environ Health Perspect 2003; 111: 1512-1518.

16 Zapletal A, Paul T, Samanek M. Die Bedeutung heutiger Methoden der Lungfunktionsdiagnostik zur Feststellung einer Obstruktion der Atemwege bei Kindern und Jugendlichen [Significance of current methods of lung function assessment for establishing airways obstruction in children and adolescents]. Z Erkrank Atem-Org 1977; 149: 525-550.

17 Armitage P, Berry G. Statistical methods in medical research. 3rd Edn. Oxford, Blackwell Science, 1994; pp. 358-366.

18 Peat JK, Toelle BG, Salome CM, Woolcock AJ. Predictive nature of bronchial responsiveness and respiratory symptoms in a one year cohort study of Sydney schoolchildren. Eur Respir J 1993; 6: 662-669. 
19 Carey VJ, Weiss ST, Tager IB, Leeder SR, Speizer FE. Airways responsiveness, wheeze onset, and recurrent asthma episodes in young adolescents. The East Boston Childhood Respiratory Disease Cohort. Am J Respir Crit Care Med 1996; 153: 356-361.

20 Laprise C, Boulet LP. Asymptomatic airway hyperresponsiveness: a three-year follow-up. Am J Respir Crit Care Med 1997; 156: 403-409.

21 Rasmussen F, Lambrechtsen J, Siersted HC, Hansen HS, Hansen NC. Asymptomatic bronchial hyperresponsiveness to exercise in childhood and the development of asthma related symptoms in young adulthood: the Odense Schoolchild Study. Thorax 1999; 54: 587-589.

22 Palmer LJ, Rye PJ, Gibson NA, Burton PR, Landau LI, Lesouef PN. Airway responsiveness in early infancy predicts asthma, lung function, and respiratory symptoms by school age. Am J Respir Crit Care Med 2001; 163: 37-42.

$23 \mathrm{Nja} \mathrm{F}$, Roksund OD, Carlsen KH. Eosinophil cationic protein $(\mathrm{ECP})$ in school children living in mountainous area of Norway: a population-based study of ECP as a tool for diagnosing asthma in children with reference values. Allergy 2001; 56: 138-144.

24 Guieterrez V, Prieto L, Torres V, et al. Relationship between induced sputum cell counts and fluid-phase eosinophil cationic protein and clinical or physiologic profiles in mild asthma. Ann Allergy Asthma Immunol 1999; 82: 559-565.

25 Wilson NM, James A, Uasuf C, et al. Asthma severity and inflammatory markers in children. Pediatr Allergy Immunol 2001; 12: 125-132. 